\title{
Meningioma in cervical spinal cord segment 6 of a dog - a case report
}

\author{
Ciprian Andrei Ober ${ }^{1}$, Orit Chai ${ }^{2}$, Joshua Milgram² ${ }^{2}$ Cosmin Petru Peștean ${ }^{1}$, \\ Cecilia Danciu ${ }^{1}$, Teodoru Soare ${ }^{3}$, Liviu Ioan Oana ${ }^{1}$, Marian Taulescu ${ }^{1}$ \\ ${ }^{1}$ University of Agricultural Sciences and Veterinary Medicine, Faculty of Veterinary Medicine, \\ Cluj-Napoca, Romania \\ ${ }^{2}$ Hebrew University of Jerusalem, Koret School of Veterinary Medicine, Rehovot, Israel \\ ${ }^{3}$ University of Agricultural Sciences and Veterinary Medicine, Faculty of Veterinary Medicine, \\ Bucharest, Romania \\ Received November 28, 2017 \\ Accepted August 13, 2018
}

\begin{abstract}
Meningiomas in dogs occur more commonly in the brain than in the cranial spinal cord. Intramedullary spinal cord tumours in dogs are described infrequently and present a diagnostic and therapeutic challenge. A nine-year-old Beagle dog was referred because of tetraparesis of a 20-day duration. The neurological signs were suggestive of a selective lesion involving the cervical spinal cord. Sagittal T2-weighted magnetic resonance imaging of the cervical vertebral column revealed a ventral, well-circumscribed mass within the vertebral canal at the level of cervical segment 6 (C6). A primary neoplasia was considered as probable differential diagnosis. The mass was removed by cervical laminectomy, durotomy and gentle dissections. On the basis of histological and immunohistochemical findings, a diagnosis of transitional meningioma (grade I) was made. Treatment of the meningioma with surgery resulted in a complete recovery, the dog was able to walk 21 days after surgery and had normal walk two months after presentation. Clinicopathologic and treatment data of cranial intraspinal meningiomas have been reported sporadically, but a segment 6 location was not thoroughly described before.
\end{abstract}

Grading system, canine, tumour

Meningioma is the most common primary nervous system tumour of the spinal cord of the dog (Wright 1985; Drost et al. 1996; Levy et al. 1997; Petersen et al. 2008; Wu et al. 2011). Because of striking similarities between canine and human meningiomas (Kraft et al. 1997), the human World Health Organization (WHO) classification system has been applied to canine meningiomas in the recent years (Sturges et al. 2008; Mandara et al. 2010). Typically, intraspinal meningiomas cause a chronic, progressive myelopathy with mild to moderate spinal pain (Fingeroth et al. 1987; Bell et al. 1992; Vanwinkle et al. 1994; Auger et al. 1996; Forterre et al. 2002; De Bosschere et al. 2003; Dunie-Merigot and Huneault 2006). Middle-aged to older dogs and cats are most commonly affected (Koestner and Higgins 2002; Montoliu et al. 2006). Meningiomas develop from the neoplastic transformation of arachnoid (meningothelial) cells (Kepes 1986; Burger and Scheithauer 2007). Their highly diverse microscopical appearance might be explained by the dual contribution of mesoderm and neural crest to meningeal development (O'Rahilly and Müller 1986), providing the capacity for neoplastic arachnoid cells to undergo mesenchymal and epithelial differentiation (Kepes 1986). While the thoracic spine is the most common location of spinal meningiomas in humans $(80 \%)$, canine spinal meningiomas are more frequent in the cranial part of the cervical spinal cord (Fingeroth et al. 1987; Levy et al. 1997; Barnhart et al. 2002; Montoliu et al. 2006; Beall et al. 2007; Petersen et al. 2008). Definitive diagnosis is essential and requires biopsy and histopathological examination. A tentative diagnosis is often possible based on tumour characteristics using advanced imaging techniques (José-López et al. 2013).

Address for correspondence:

Ciprian Ober

Faculty of Veterinary Medicine

University of Agricultural Sciences and Veterinary Medicine

Calea Manastur St. 3-5, 400372, Cluj-Napoca, Romania

Phone: +40749262180

E-mail: ciprian.ober@usamvcluj.ro

http://actavet.vfu.cz/ 
Typical magnetic resonance imaging characteristics include a contrast-enhancing mass with a broad-based dural attachment and variable signal intensity on precontrast T1- and T2- weighted images (Vanwinkle et al. 1994; Drost et al. 1996; Kippenes et al. 1999; McDonnell et al. 2005). Most histopathologic characteristics of canine meningiomas are strikingly similar to those in humans (Koestner et al. 1999; Kleihues and Cavenee 2000; Sturges et al. 2008). Tumour grading is an important diagnostic criterion in human intracranial meningiomas and has both predictive and prognostic values (Kleihues and Cavenee 2000). Although several reports have described various histologic subtypes in canine spinal cord meningiomas, tumour grading is rarely used (Barnhart et al. 2000; Theon et al. 2000). The aim of this study was to describe the clinical, imaging and pathologic characteristics of a meningioma in a rare location at the level of cervical spinal cord segment 6 in a dog.

\section{Case presentation}

A 9-year-old, male intact Beagle was admitted with a 20-day history of right thoracic limb monoparesis that progressed to ambulatory tetraparesis. No traumatic incident was reported by the owners. On neurologic examination there was moderate ambulatory tetraparesis, worse on the right side. Postural reactions were absent in the right thoracic limb and delayed in the other limbs. The rest of the neurological examination was unremarkable. Results of the complete blood count, serum biochemical profile, thoracic radiographs, and abdominal ultrasonography were within normal limits. Survey radiographs of the vertebral column under general anaesthesia did not reveal abnormalities. Sagittal T2-weighted magnetic resonance imaging of the cervical vertebral column revealed a ventral, well-circumscribed mass in the vertebral canal over the $6^{\text {th }}$ cervical vertebra (C6) (Plate III, Fig. 1A,B). The spinal cord was severely compressed at this level by the mass. The cerebrospinal fluid analysis results were unremarkable.

After premedication with diazepam (Terapia SA, Romania) $(0.2 \mathrm{mg} / \mathrm{kg}$ intravenously, anaesthesia was induced with propofol (Lipuro 1\%, Braun Melsungen AG, Germany) ( $4 \mathrm{mg} / \mathrm{kg}$ intravenously) and maintained with isoflurane (Forane, Abbot Laboratories, UK) in oxygen. The dog was positioned in sternal recumbency with the head gently flexed in a neutral position. A dorsal approach to the caudal cervical spine was performed. The multifidus musculature on the spinous processes was elevated with a periosteal elevator to expose the dorsal bony lamina. The spinous processes and the yellow ligament were removed with a rongeur to the level of the dorsal bony lamina, which was removed with a high speed drill. The dura mater was incised using a No. 11 blade and fine tenotomy scissors. The mass and compressed spinal cord were observed (Plate III, Fig. 1C). A bipolar cautery, loupes and copious irrigation with suction to preserve visibility were used. Tumour removal was done by gentle blunt dissection, creating a plane between normal tissue and the mass (Fig. 1C, D). The dural incision was not sutured. The muscles, subcutaneous tissues, and skin incision were apposed in layers. Pain management was achieved by treatment with tramadol (Ozone Laboratories Ltd, UK) (4 mg/kg orally), and carprofen (Rimadyl; Zoetis, USA) $(2 \mathrm{mg} / \mathrm{kg}$, orally). A first generation cephalosporin, cefadroxil (Antibiotice, Romania) (22 mg/kg every $8 \mathrm{~h}$, orally) was also used for 10 days postoperatively.

The dog's owner provided a written, informed consent for the clinical assessment, diagnostic work-up, treatment and follow-up of their pet and for the inclusion of their pet's information in this manuscript for publication.

\section{Histopathological and immunohistochemical examination}

For histopathological examination, tissue samples from the neoplasm were fixed in $10 \%$ phosphate buffered formalin for $24 \mathrm{~h}$, trimmed and embedded in paraffin. Sections 
were cut at $5 \mu \mathrm{m}$ and stained with haematoxylin and eosin (H\&E). Immunohistochemistry was performed to detect the origin of the neoplastic cell population. A panel of three immunohistochemical markers that included vimentin, pancytokeratin and S100 protein was selected (Table 1).

Table 1. Antibodies used for immunohistochemistry.

\begin{tabular}{llcc}
\hline Antibody & \multicolumn{1}{c}{ Source } & Antigen retrieval & Detection method \\
\hline Vimentin & Dako & Dako & EnVision \\
& Monoclonal mouse & FLEX TRS & FLEX/HRP \\
& Clone V9 & Low ph & SM \\
& M0725 & & \\
\hline S-100 & Dako & Dako & EnVision \\
& Polyclonal rabbit & FLEX TRS & FLEX/HRP \\
& Z0311 & High ph & SM 802 \\
\hline Pan-cytokeratin & Dako & Dako & EnVision \\
& Monoclonal mouse & FLEX TRS & FLEX/HRP \\
& AE1/AE3 & Low ph & SM 802 \\
\hline
\end{tabular}

Histologically, the neoplasm was well delimited, partially encapsulated and expansile, composed of two types of cell population. The first population consisted of uniform meningothelial cells arranged in lobules surrounded by thin collagenous stroma (Plate III, Fig. 2A). The second population was composed of numerous spindle-shaped cells, resembling fibroblast and forming intersecting streams embedded in a moderate amount of pale eosinophilic collagen-rich matrix. Multifocally, the neoplastic cells formed whorls or variable sized round structures of concentric layers. The latter structures were often hyalinized and slightly calcified, interpreted as psammoma bodies (Fig. 2B). The presumptive diagnosis of mixed (transitional) meningioma was made. Expression of S-100 (Fig. 2C) and vimentin (Fig. 2D) protein antibodies was represented by an intense labelling of the cell nuclei of the neoplastic cells. Pan-cytokeratin immunoexpression was diffusely negative. These findings demonstrate the mixed origin of the neoplastic cells and were compatible with the diagnosis of a transitional meningioma.

\section{Discussion}

Reports of canine meningiomas in the caudal part of the cervical spinal canal are scarce. The most meningiomas affect the spinal cord cranial to vertebra C3 (Fingeroth et al. 1987; Vanwinkle et al. 1994; McDonnell et al. 2005; Petersen et al. 2008). Of the 53 reported cases of spinal cord meningiomas for which location was mentioned (Zaki et al. 1975; Gilmore 1983; Raskin 1984; Fingeroth et al. 1987; Vanwinkle et al. 1994; Siegel et al. 1996; Levy et al. 1997; Kippenes et al. 1999; Yeomans 2000; Forterre et al. 2002; Barnhart et al. 2002; De Bosschere et al. 2003; McDonell et al. 2005; Dunie-Merigot and Huneault 2006; Petersen et al. 2008), 67\% were cervical, $4 \%$ thoracic, $23 \%$ lumbar, and $6 \%$ were multifocal. Tumour position was lateral in $32 \%$, posterolateral in $10 \%$, posterior in $3 \%$ and anterior in $13 \%$. A meningothelial cystic mass was found in a dog at the C5-C6 level (José-López et al. 2013).

A diagnosis of transitional meningioma can be confirmed by histopathological and immunohistochemical examination of tissue obtained by surgical excision or at necropsy. 
Recently, for dogs, these tumours have been graded on the basis of the mitotic count and histological criteria for malignancy, according to the WHO system for human beings (Kleihues et al. 2002), as grade I (benign), grade II (atypical), and grade III (anaplastic) (Petersen et al. 2008; Sturges et al. 2008). Most meningiomas affecting the canine spinal cord are grades I or II, while grade III tumours are rare (Petersen et al. 2008). Grade I tumours appear to be more likely to develop in older dogs and are more likely to be located in the cervical region (Petersen et al. 2008). There is no apparent correlation between the grade of tumour and imaging characteristics or the long-term outcome (Petersen et al. 2008). Cerebrospinal fluid analysis may be normal or may reveal nonspecific abnormalities and neoplastic cells are rarely identified. Cerebrospinal fluid analysis was performed in our case but no neoplastic cells were identified.

Aggressive behaviour of some spinal meningiomas has been observed. Thus, in a study of 13 spinal meningiomas (Petersen et al. 2008) four invasive tumours were identified. Diagnoses of osseous-associated cervical spondylomyelopathy or meningioma were considered the strongest variables to predict early post-operative neurological deterioration, associated with higher (more severely affected) neurological grade before surgery and longer surgery time.

Reported treatments for canine intraspinal meningiomas consist of medical management and cytoreductive surgery with or without radiation therapy (Raskin 1984; Fingeroth et al. 1987; Bell et al. 1992; Vanwinkle et al. 1994; Auger et al. 1996; Siegel et al. 1996; Levy et al. 1997; Forterre et al. 2002; De Bosschere et al. 2003; Dunie-Merigot and Huneault 2006; McDonnell et al. 2005). Survival times after surgery vary from 4 to 47 months (Fingeroth et al. 1987; Bell et al. 1992; Vanwinkle et al. 1994; Auger et al. 1996; Levy et al. 1997; Forterre et al. 2002; De Bosschere et al. 2003; Dunie-Merigot and Huneault 2006). The effect of adjunctive radiation therapy on the survival time is unclear, because there are only a few reports describing its use (Bell et al. 1992; Siegel et al. 1996; McDonnell et al 2005).

Surgical gross total tumour removal of vertebral tumours improves the quality of life (Besalti et al. 2016). No surgical complications were observed in our case. The duration of hospitalisation was seven days. Paresis and absent pelvic limb postural reactions were still present in the first five days but the dog was able to rise and make a few steps with assistance after seven days post operation. Noticeable ataxia with some limb deficits were observed by the owner in the first month after discharge, but no cervical hyperaesthesia was noticed. Progressive neurological improvement was reported by the owner with a complete resolution of neurological signs observed two months after surgery at a follow-up at our clinic. We did not perform any restaging of this tumour.

\section{Acknowledgements}

The authors gratefully acknowledge Cornel CĂTOI, Rector of University of Agricultural Sciences and Veterinary Medicine, Cluj-Napoca, and the dog's owner for their support of this work.

\section{References}

Auger JM, Miller CW, Smith Maxie LL, Bateman KE, Duignan PJ 1996: Lumbar meningioma in a dog. Vet Comp Orthop Traumatol 9: 140-144

Barnhart KF, Wojcieszyn J, Storts RW 2002: Immunohistochemical staining patterns of canine meningiomas and correlation with published immunophenotypes. Vet Pathol 39: 311-321

Beall DP, Googe DJ, Emery RL, Thompson DB, Campbell SE, Ly JQ, DeLone D, Smirniotopoulos J, Lisanti C, Currie TJ 2007: Extramedullary intradural spinal tumors: A pictorial review. Curr Probl Diagn Radiol 36 $185-198$

Bell FW, Feeney DA, O’Brien TJ, Caywood DD, Hultgren BD 1992: External beam radiation-therapy for recurrent intraspinal meningioma in a dog. J Am Anim Hosp Assoc 28: 318-322

Besalti O, Caliskan M, Can P, Vural SA, Algin O, Ahlat O 2016: Imaging and surgical outcomes of spinal tumors in 18 dogs and one cat. J Vet Sci 30: 225-234 
Burger PC, Scheithauer BW 2007: Meningioma. In: Silverberg SG. Tumors of the Central Nervous System. AFIP Atlas of Tumour Pathology, Series 4, Fascicle 7, Washington DC: American Registry of Pathology and Armed Forces Institute of Pathology P. 331-362

De Bosschere H, Vermeersch K, Tshamala M, Van De Velde B, Hoybergs Y, Van Ham L, Ducatelle R 2003: Lumbar atypical meningioma in a dog. Vlaams Diergeneeskd Tijdschr 72: 295-298

Drost WT, Love NE, Berry CR 1996: Comparison of radiography, myelography and computed tomography for the evaluation of canine vertebral and spinal cord tumors in sixteen dogs. Vet Radiol Ultrasound 28-33

Dunie-Merigot AHL, Huneault L 2006: Meningiome medullaire chez un chien. Point Vet 72-75

Fingeroth JM, Prata RG, Patnaik AK 1987: Spinal meningiomas in dogs-13 cases (1972-1987). J Am Vet Med Assoc 191: 720-726

Forterre F, Kaiser S, Matiasek K, Schmahl W, Brunnberg L 2002: Spinal cord canal tumor in dogs: 33 cases (retrospective study). Kleintierpraxis 47: 357-364

Gilmore DR 1983: Neoplasia of the cervical spinal-cord and vertebrae in the dog. J Am Anim Hosp Assoc 19: 1009-1014

José-López R, de la Fuente C, Pumarola M, Aňor S 2013: Spinal meningiomas in dogs: description of 8 cases including a novel radiological and histopathological presentation. Can Vet J 54: 948-954

Kepes JJ 1986: Presidential address: the histopathology of meningiomas. A reflection of origins and expected behavior? J Neuropathol Exp Neurol 45: 95-107

Kippenes H, Gavin PR, Bagley RS, Silver GM, Tucker RL, Sande RD 1999: Magnetic resonance imaging features of tumors of the spine and spinal cord in dogs. Vet Radiol Ultrasound 40: 627-633

Kleihues P, Cavenee WK 2000: World Health Organization Classification of Tumours, International Agency for Research on Cancer (IARC) Pathology and Genetics of Tumours of the Nervous System. Lyon, France: IARC Press

Kleihues P, Louis DN, Scheithauer BW, Rorke LB, Reifenberger G, Burger PC, Cavenee WK 2002: The WHO classification of tumors of the nervous system. J Neuropathol Exp Neurol 61: 215-225

Koestner A, Bilzer T, Fatzer R 1999: Histologic Classification of Tumors of the Nervous System of Domestic Animals. $2^{\text {nd }}$ edn, Washington, DC: Armed Forces Institute of Pathology

Koestner A, Higgins RJ 2002: Tumors of the nervous system. In: Meuten DJ (Ed): Tumors in Domestic Animals. $4^{\text {th }}$ edn, Iowa State Press: Ames p. 697-738

Kraft SL, Gavin PR, DeHaan C, Moore M, Wendling LR, Leathers CW 1997: Retrospective review of 50 canine intracranial tumours evaluated by magnetic resonance imaging. J Vet Intern Med 11: 218-225

Levy MS, Kapatkin AS, Patnaik AK, Mauldin, GN, Mauldin GE 1997: Spinal tumors in 37 dogs: clinical outcome and long-term survival (1987-1994). J Am Anim Hosp Assoc 33: 307-312

Mandara MT, Pavone S, Brunetti B, Mandrioli L 2010: Comparative study of canine and feline meningioma classification based on the WHO histological classification system in humans. J Vet Intern Med 24: 238

McDonnell JJ, Tidwell AS, Faissler D, Keating J 2005: Magnetic resonance imaging features of cervical spinal cord meningiomas. Vet Radiol Ultrasound 46: 368-374

Montoliu P, Anor S, Vidal E, Pumarola M 2006: Histological and immunohistochemical study of 30 cases of canine meningioma. J Comp Pathol 135: 200-207

O'Rahilly R, Müller, F 1986: The meninges in human development. J Neuropathol Exp Neurol 45: 588-608

Petersen SA, Sturges BK, Dickinson PJ, Pollard RE, Kass PH, Kent M, Vernau KM, Lecouteur LA, Higgins RJ, 2008: Canine intraspinal meningiomas: imaging features, histopathologic classification, and long-term outcome in 34 dogs. J Vet Intern Med 22: 946-953

Raskin RE 1984: An atypical spinal meningioma in a dog. Vet Pathol 21: 538-540

Siegel S, Kornegay JN, Thrall DE 1996: Postoperative irradiation of spinal cord tumors in 9 dogs. Vet Radiol Ultrasound 37: 150-153

Sturges BK, Dickinson PJ, Bollen AW, Koblik PD, Kass PH, Kortz GD, Vernau KM, Knipe MF, Lecouteur RA, Higgins RJ 2008: Magnetic resonance imaging and histological classification of intracranial meningiomas in 112 dogs. J Vet Intern Med 22: 586-595

Theon AP, Lecouteur RA, Carr EA, Griffey SM 2000: Influence of tumor cell proliferation and sex-hormone receptors on effectiveness of radiation therapy for dogs with incompletely resected meningiomas. J Am Vet Med Assoc 216: 701-707

Vanwinkle TJ, Steinberg HS, Decarlo AJ, Dayrell-Hart B, Steinberg SA, Smith CA, Summers BA 1994: Myxoid meningiomas of the rostral cervical spinal-cord and caudal fossa in 4 dogs. Vet Pathol 31: 468-471

Wright JA 1985: The pathological features associated with spinal tumours in 29 dogs. J Comp Pathol 95: 549-557

Wu YT, Ho JT, Lin YJ, Lin JW 2011: Rhabdoid papillary meningioma: a clinicopathologic case series study. Neuropathology 31: 599-605

Yeomans SM 2000: Extensive spinal meningioma in a young dog. J Comp Pathol 122: 303-306

Zaki FA, Prata RG, Hurvitz AI, Kay WJ 1975: Primary tumors of spinal-cord and meninges in 6 dogs. J Am Vet Med Assoc 166: 511-517 
Plate III

Ober C. et al.: Meningioma in cervical ... pp. 225-229
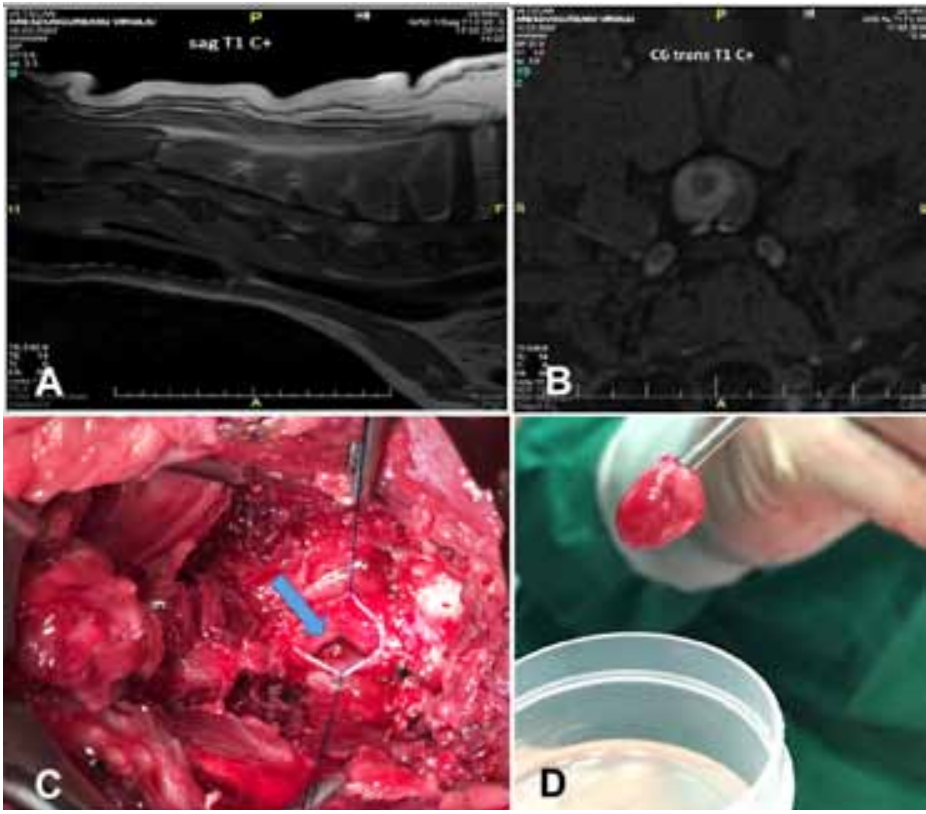

Fig. 1 Sagittal (A) and axial (B) T2-weighted magnetic resonance imaging of the cervical vertebral column. A single intra-axial, well-circumscribed lesion involving the right ventrolateral aspect of the spinal cord over the C6 is observed. C) Intraoperative aspect (note the cord compression, blue arrow). D) Gross appearance of the mass after excision.

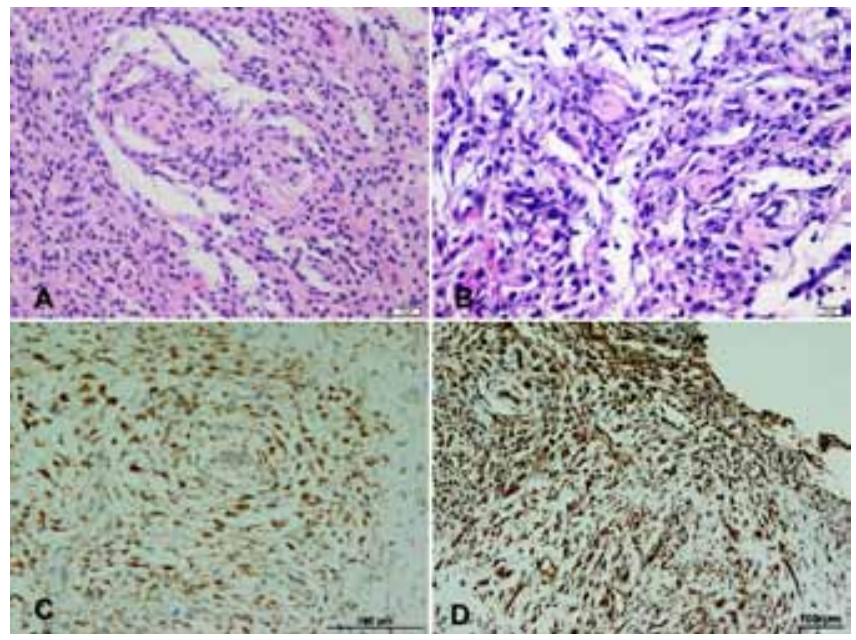

Fig. 2. Histological and immunohistochemical features of the transitional meningioma (grade I). A) The photomicrophotograph showing a lobular arrangement of the neoplastic meningothelial cells admixed with numerous spindle-like cells. Haematoxylin and eosin stain. B) The neoplastic cells form multifocal round structures of concentric layers, which are often hyalinized and slightly calcified (psammoma bodies). $\mathrm{C}$ and D) Positive immunohistochemical expression of S-100 protein (C) and vimentin (D) antibodies characterized by an intense labelling of the cytoplasm of the neoplastic cells. Streptavidin-biotin complex, DAB-horseradish peroxidase, Mayer's haematoxylin counterstain 